Tropical Journal of Pharmaceutical Research May 2015; 14(5): 769-776

ISSN: $1596-5996$ (print); 1596-9827 (electronic)

(C) Pharmacotherapy Group, Faculty of Pharmacy, University of Benin, Benin City, 300001 Nigeria.

All rights reserved.

Available online at http://www.tjpr.org

Original Research Article

http://dx.doi.org/10.4314/tjpr.v14i5.4

\title{
Protective Effects of Tetrahydrocurcumin and Curcumin against Doxorubicin and Cadmium-Induced Cytotoxicity in Chang Liver Cells
}

\author{
Nuntiya Somparn ${ }^{1 *}$, Veerapol Kukongviriyapan², Upa Kukongviriyapan², \\ Laddawan Senggunprai ${ }^{2}$ and Auemduan Prawan $^{2}$ \\ ${ }^{1}$ Division of Pharmacology, Preclinical Science, Faculty of Medicine, Thammasat University, ${ }^{2}$ Department of Pharmacology, 3 \\ Department of Physiology, Faculty of Medicine, Khon Kaen University, Khon Kaen, Thailand \\ *For correspondence: Email: nuntiya_tom@hotmail.com; Tel/Fax: +66-2926-9710
}

\begin{abstract}
Purpose: To investigate the cytoprotective effect of tetrahydrocurcumin, (THC) and curcumin (CUR) on cytotoxicity induced by doxorubicin and cadmium in Chang liver cells.

Methods: Cytotoxicity was determined by sulforhodamine $B$ assay. The expression of nuclear factorerythroid-2-related factor 2 (Nrf2) Nrf2 regulated cytoprotecetive enzymes, glutamylcysteine ligase catalytic subunit (GCLC) and NADP (H): quinone oxidoreductase1 (NQO1) was determined by Western blot analysis. Nuclear translocation of Nrf-2 was analyzed by immunofluorescence method. The level of superoxide formation was assayed by chemiluminescence method.

Results: Treatment with THC or CUR significantly induced GCLC and NQO1 expression and the nuclear translocation of Nrf2. Exposure to doxorubicin (DOX) or Cd for $24 \mathrm{~h}$ induced cell death of about $50 \%$. However, pre-treatment with THC or CUR (1 or $6 \mu \mathrm{M})$ for $24 \mathrm{~h}$ significantly increased cell survival to 80 or $90 \%$, respectively $(p<0.05)$. Similar pre-treatment with THC or CUR significantly protected against Cd-induced cell death by a level of 80 and $85 \%$, respectively $(p<0.05)$. The cytoprotective effect of these compounds was associated with suppressed DOX- and Cd-induced superoxide formation and induction of GCLC and NQO1 expression.

Conclusions: THC mediates its effects by activation of Nrf2 and its regulated enzymes, GCLC and NQO1. Induction of GCLC, NQO1 protein expression and suppression of superoxide are associated with the cytoprotective effect.
\end{abstract}

Keywords: Chang hepatocyte, Curcumin, Tetrahydrocurcumin, Cytoprotection, Doxorubicin, Cadmium

Tropical Journal of Pharmaceutical Research is indexed by Science Citation Index (SciSearch), Scopus, International Pharmaceutical Abstract, Chemical Abstracts, Embase, Index Copernicus, EBSCO, African Index Medicus, JournalSeek, Journal Citation Reports/Science Edition, Directory of Open Access Journals (DOAJ), African Journal Online, Bioline International, Open-J-Gate and Pharmacy Abstracts

\section{INTRODUCTION}

Curcumin (CUR) is a phenolic compound from Curcuma longa. A variety of pharmacological effects of CUR (anti-inflammatory and antioxidant) have been reported [1]. The poor absorption of CUR particularly in humans has raised several concerns that this may limit its clinical utility $[2,3]$. Recently, tetrahydrocurcumin
(THC), a colorless derivative of CUR and one of the major metabolites of CUR [4] has been shown to possess cardioprotective effects against oxidative stress-induced injury similar to CUR with comparable potency in in vivo studies $[5,6]$. Moreover, THC probably has better oral bioavailability and better antioxidant in vivo than CUR [7]. Furthermore, THC has been 
increasingly used in cosmetic products since it is colorless and is suitable for product formulation.

Besides direct antioxidant activity, the indirect antioxidant effect of CUR is suggested to be mediated by activation of nuclear factorerythroid-2-related factor 2 (Nrf2), subsequently leading to trans-activation of antioxidant and cytoprotective genes including glutamylcysteine ligase catalytic subunit (GCLC) and NADP $(H)$ : quinone oxidoreductase 1[8]. NQO1 is an enzyme involved in detoxification reaction by catalyzing two electron reduction, and regulation of cellular redox [9]. On the other hand, GCLC has a critical role to protect cells against damage caused by oxidative stress. The enzyme catalyzes the rate-limiting step in the synthesis of glutathione (GSH) which is the most abundant intracellular antioxidant molecule [10]. However, there are only few reports comparing the effect of THC with CUR at molecular level especially the transcriptional effect of THC on cytoprotective genes.

The objective of this study was to evaluate the cytoprotective effect of THC in association with activation of Nrf2 transcription factor and its regulated enzymes, GCLC and NOQ-1, in comparison with CUR, using HeLa [Chang liver] cells. To study the cytoprotective effect of CUR and THC against free radicals or oxidative stress, doxorubicin (DOX) and cadmium (Cd) -induced cytotoxicity were used as the models.

\section{EXPERIMENTAL}

\section{Materials}

Curcuminoids (CUR) (> $99 \%$ purity) and THC (> $99 \%$ purity) were obtained from the Research and Development Institute, Government Pharmaceutical Organization, Thailand. The purity of the compounds was analyzed by an HPLC method.

\section{Cell culture}

HeLa (Chang liver) cells (ATCC CCL-13) were routinely cultured in Ham's F12 media supplemented with $12.5 \mathrm{mM} \quad \mathrm{N}-2-$ hydroxyethylpiperazine-NO-2-ethanesulfonic acid (HEPES), pH 7.3; $100 \mathrm{U} / \mathrm{mL}$ penicillin, 100 unit $/ \mathrm{mL}$ streptomycin sulfate, and $10 \%$ fetal calf serum.

\section{Cytotoxicity assay}

Cytotoxicity was determined by sulforhodamine $B$ (SRB) colorimetric assay [12]. Briefly, the cells were washed with phosphate buffered saline (PBS), fixed with $10 \%(\mathrm{w} / \mathrm{v})$ trichloroacetic acid and stained with $0.4 \%$ SRB for $30 \mathrm{~min}$, after washing repeatedly with $1 \%(\mathrm{v} / \mathrm{v})$ acetic acid. The protein-bound dye was dissolved in $10 \mathrm{mM}$ Tris base solution $\mathrm{pH}$ 10.5. The optical density was read at $540 \mathrm{~nm}$ using a microplate reader. In the cytoprotective study, the cells were pretreated with CUR or THC for $24 \mathrm{~h}$ followed by exposure to DOX or $\mathrm{Cd}$ for another $24 \mathrm{~h}$ before assessment by SRB assay.

\section{Western blot analysis}

Chang cells were cultured in $100 \mathrm{~mm}^{3}$ dishes and treated with DOX or $\mathrm{Cd}$ or combinations of THC or CUR with DOX or Cd. The cultured cells were washed with PBS, lysed with Radioimmunoprecipitation assay buffer (RIPA buffer) with addition of protease inhibitor cocktail at $4{ }^{\circ} \mathrm{C}$ for $15 \mathrm{~min}$ and transferred to a microtube. After vigorous vortex mixing, the suspension was centrifuged at $12,000 \mathrm{~g}$ for $20 \mathrm{~min}$ and the supernatant was collected and stored at $-20{ }^{\circ} \mathrm{C}$ until use. The protein samples $(20 \mu \mathrm{g})$ were separated by $8-10 \%$ SDS-polyacrylamide gel electrophoresis and transferred to polyvinylidene difluoride (PVDF) membranes. The membranes were blocked for $1 \mathrm{~h}$ at room temperature with 5 $\%(\mathrm{w} / \mathrm{v})$ skimmed milk powder in Tris buffered saline (TBS) containing $0.1 \%$ Tween-20. The PVDF membrane was incubated overnight at $40 \mathrm{C}$ with primary antibodies of goat polyclonal anti-human NQO-1 (sc-16464, Santa Cruz Biotechnology), rabbit polyclonal anti-human GCLC (sc-28965, Santa Cruz Biotechnology) and goat polyclonal anti-human $\square$-actin (sc-8432 HRP, Santa Cruz Biotechnology) in PBS. After washing with PBS the blots were incubated for 1 $h$ at room temperature with the HRP conjugated secondary antibodies (anti-rabbit IgG-HRP sc2004 and anti-goat IgG-HRP sc-2354, Santa Cruz Biotechnology). After removal of the secondary antibody and TBS buffer washes, the blots were incubated in ECL substrate solution (Super Signal West Pico Chemiluminescent Substrate: ThermoScientific, IL, USA). The densities of the specific protein bands were visualized and captured by Image Quant TM 400 (GE HealthCare).

\section{Immunofluorescence detection of Nrf2 nuclear translocation}

Cells were plated on sterilized coverslips and placed in 6 well plates for $24 \mathrm{~h}$, then treated with CUR or THC for $24 \mathrm{~h}$. After treatment, the cells were fixed with $4 \%$ formaldehyde, permeabilized with $0.2 \%$ Triton X-100 and blocked in $5 \%$ BSA in PBS for $2 \mathrm{~h}$. The coverslips were incubated 
with primary anti-bodies of rabbit anti-Nrf2 polyclonal antibody (sc-722, Santa Cruz Biotechnology) in $0.2 \%$ BSA in PBS overnight at $4{ }^{\circ} \mathrm{C}$. After washing with PBS, secondary antibody donkey anti-rabbit IgG H\&L (Alexa Fluor®488, ab150073, Abcam, Cambridge, MA, USA) were added and incubated for $40 \mathrm{~min}$. The coverslips were mounted onto glass slides using ProLong®Gold antifade reagent with DAPI (Molecular Probes, Life Technologies, Grand Island, NY, USA). Fluorescence images were captured on a Nikon fluorescence microscope. The fluorescence data were analyzed by Nikon's NIS-Elements imaging software version 4.0. The fluorescent intensity of Nrf2 was quantified by measuring the area and fluorescent signal intensity of nrf2 in nuclear and cytoplasm. The DAPI staining mask was used to define the nuclear region of interest (ROI) and the cytoplasmic ROI is defined by the whole cell region subtracted by the DAPI mask. Thus, the results were expressed as integrated optical density (IOD): IOD $=$ area $x$ intensity of fluorescence. To eliminate the variable of the staining in each image, fluorescence signals of each image was corrected by its background signal. The nuclear and cytoplasmic IOD were compared and found to be a relative measure of Nrf-2 nuclear translocation.

\section{Determination of superoxide formation}

The lucigenin-enhanced chemiluminescence method is used for detecting superoxide anion according to the previously described method
[13]. In brief, Chang cells were cultured in 35-mm dishes overnight, and replaced with fresh media supplemented with CUR or THC $6 \mu \mathrm{M}$ for $24 \mathrm{~h}$ and followed by the addition of $1 \mu \mathrm{M}$ DOX or Cd $3 \mu \mathrm{M}$ for another $3 \mathrm{~h}$. The cultures were washed with PBS and the superoxide formation was measured using lucigenin as a substrate with a luminometer (Model 20/20n, Turner Biosystem).

\section{Statistical analysis}

Data are presented as mean \pm SEM. Analysis of variance (ANOVA) with Duncan post-hoc test was used to determine significant differences between groups. An ANOVA on rank test was also performed for non-parametric test. The level of significance was set at $p<0.05$.

\section{RESULTS}

CUR and THC induced GCLC and NQO-1 expression in association with induction of Nrf2- translocation in Chang liver cells

Treatment with THC $(0.1-10 \mu \mathrm{M})$ or CUR $(0.1$ $6 \mu \mathrm{M}$ ) for $24 \mathrm{~h}$ did not cause cytotoxicity in Chang cells. However, the cytotoxicity was found in $10 \mu \mathrm{M}$ CUR-treated cells (data not shown). Therefore, $6 \mu \mathrm{M}$ THC and CUR were selected for this study. THC, as well as CUR significantly induced GCLC (Fig 1A) and NQO-1 expression (Fig 1B).
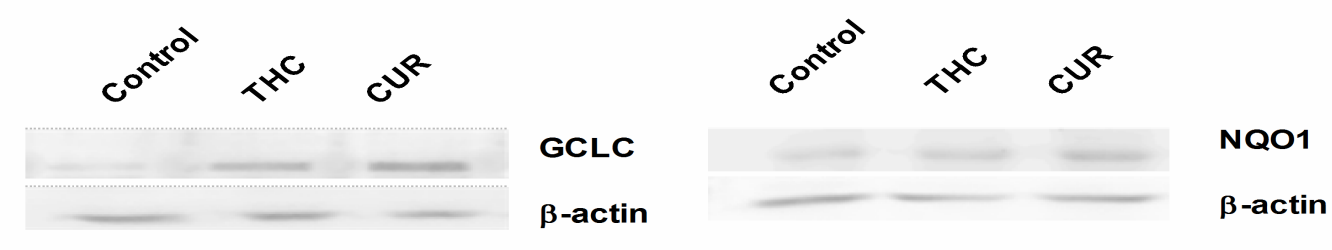

GCLC
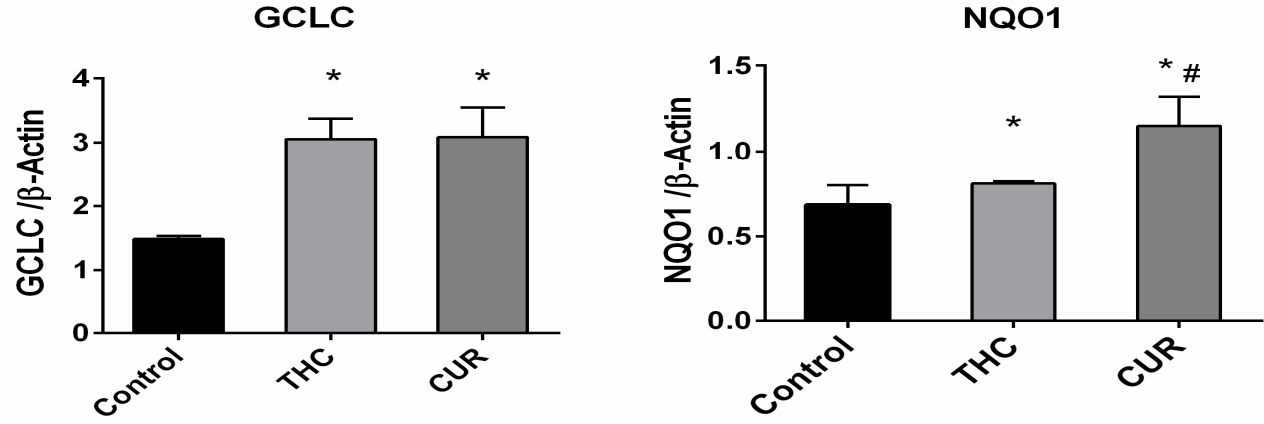

Figure 1: Effect of THC and CUR on GCLC and NQO-1 expressions. The cultured cells were pre-treated with 6 $\mu \mathrm{M}$ THC or CUR for $24 \mathrm{~h}$. The effects of treatments on GCLC (A) and NQO-1 expression (B) were analyzed by Western immunoblotting. The images shown were representative of experiments with similar results. Each bar represents the mean \pm SEM $(n=3) ;{ }^{*} p<0.05$ compared with control; ${ }^{*} p<0.05$ compared with THC-treated group 
The immunofluorescent staining of Nrf2 in nuclear and cytoplasmic compartments of Chang cells was analyzed (Fig 2A and 2B). Consistent with induction of GCLC and NQO-1 protein expressions, activation of Nrf2 was also found. The activation of Nrf2 was represented by the increased ratios of Nrf2 in nucleus and cytoplasm in THC and CUR treated groups compared with control (Fig 2C).

\section{Cytoprotective effect of THC and CUR in DOX and $\mathrm{Cd}$-induced cytotoxicity}

Treatment with THC or CUR at a concentration of 1 or $6 \mu \mathrm{M}$ alone for $48 \mathrm{~h}$ minimally affected cell viability (Fig $3 \mathrm{~A}$ and $\mathrm{B}$ ). Exposure to DOX or $\mathrm{Cd}$ induced cell death in dose-dependent manner. At high concentrations, DOX or $\mathrm{Cd}$ induced about $50 \%$ cell death (Fig 3 ).
Pre-treatment with THC and CUR significantly increased cell survival up to 80 and $90 \%$, respectively, compared to DOX-treated controls. The cytoprotective effect of CUR was slightly more potent than that of THC, particularly when both compounds were compared at low concentration of CUR and THC (Fig 3A). For Cd, pre-treatment with THC or CUR significantly increased cell survival when compared to $\mathrm{Cd}$ treated controls (Fig.3B). At high concentration of $\mathrm{Cd}$, pre-treatment with $6 \mu \mathrm{M}$ CUR showed a slightly higher protective effect than THC. Over all, CUR was slightly more potent than THC in cytoprotective effect. It should be noted that both CUR and THC were less efficacious in cytoprotection against $\mathrm{Cd}$ toxicity compared with DOX.
A

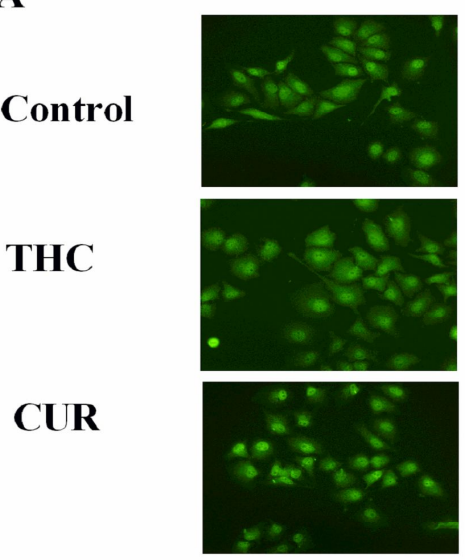

B
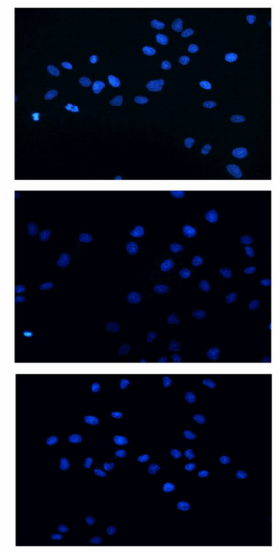
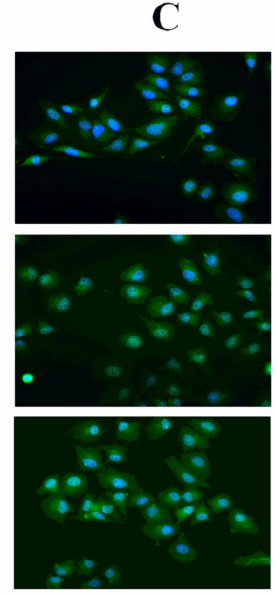
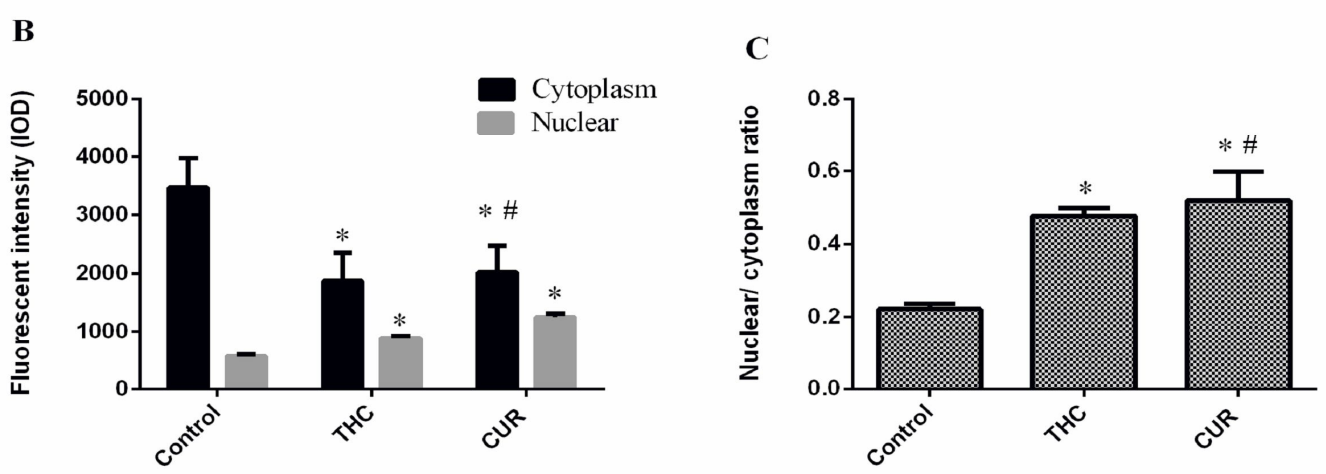

Figure 2: Nrf2 immunofluorescence staining in Chang cells. The cells were treated with $6 \mu \mathrm{M}$ THC or CUR for $24 \mathrm{~h}$. Cultured cells were stained with antibody against Nrf2 (A) and DAPI (B) are shown. The sequential processing of these images was shown to produce binary masks of nuclear and cytoplasmic regions of interest (ROI). The nuclear ROI is defined by the DAPI mask and the cytoplasmic ROI is defined by subtracting the DAPI mask (C). Quantification of Nrf2 fluorescence intensity was analyzed using Nikon's NIS-Elements imaging software version 4.0. Each bar represents the mean \pm SEM from five separated images; ${ }^{*} p<0.05$ compared with control; ${ }^{\S} p<0.05$ compared with THC treated-group at the corresponding treatment 


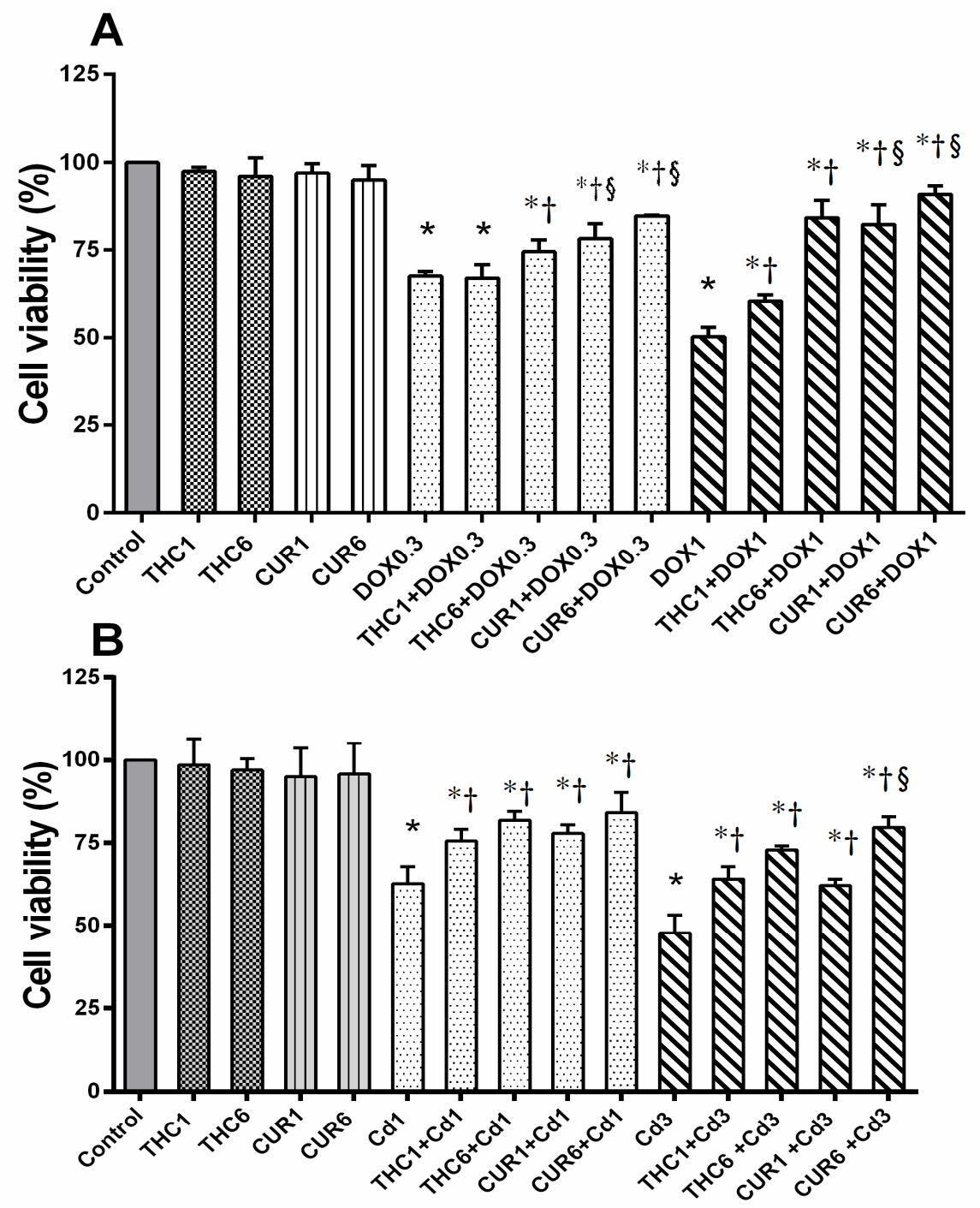

Figure 3: Protective effects of THC and CUR against DOX- or Cd-induced toxicity. Chang cells were pretreated with THC or CUR $(1$ or $6 \mu \mathrm{M})$ at $37^{\circ} \mathrm{C}$ for $24 \mathrm{~h}$ followed by co-treatment with DOX $(0.3-1 \mu \mathrm{M})(\mathrm{A})$ or Cd $(1-3$ $\mu \mathrm{M})(\mathrm{B})$ for another $24 \mathrm{~h}$. Cell cytotoxicity was analyzed by sulforhodamine B assay. Each bar represents the mean \pm SEM from three experiments. ${ }^{*} p<0.05$ compared with the control; ${ }^{\dagger} p<0.05$ compared with DOX- or Cdtreated at the corresponding concentration; ${ }^{\S} p<0.05$ compared with CUR at the corresponding concentration

\section{Radical scavenging effect of THC and CUR}

DOX and $\mathrm{Cd}$ alone induced large amount of superoxide formation (Fig 4). Consistent with their cytoprotective effects, THC and CUR significantly suppressed DOX-induced reactive oxygen species (ROS) formation in pre-treated cells. On the other hand, Cd-induced ROS formation was significantly suppressed by both compounds, but to a smaller extent than in DOXmodel. This indicates the association of cytoprotective and radical scavenger activity of both substances, where THC and CUR are of comparable activity (Fig 4).

\section{Effects of THC and CUR on DOX- and Cd- induced expression of GCLC and NQO1}

Treatment with DOX or $\mathrm{Cd}$ alone also induced GCLC and NQO-1 expression (Fig 5A and B). Combination of DOX or Cd with CUR significantly further increased GCLC and NQO1 expression when compared with DOX or $\mathrm{Cd}$ alone. THC, on the hand, did not enhance GCLC expression when cells were treated with DOX or Cd. (Fig 5A). However, THC enhanced NQO1 expression in both DOX and Cd models (Fig.5B). 


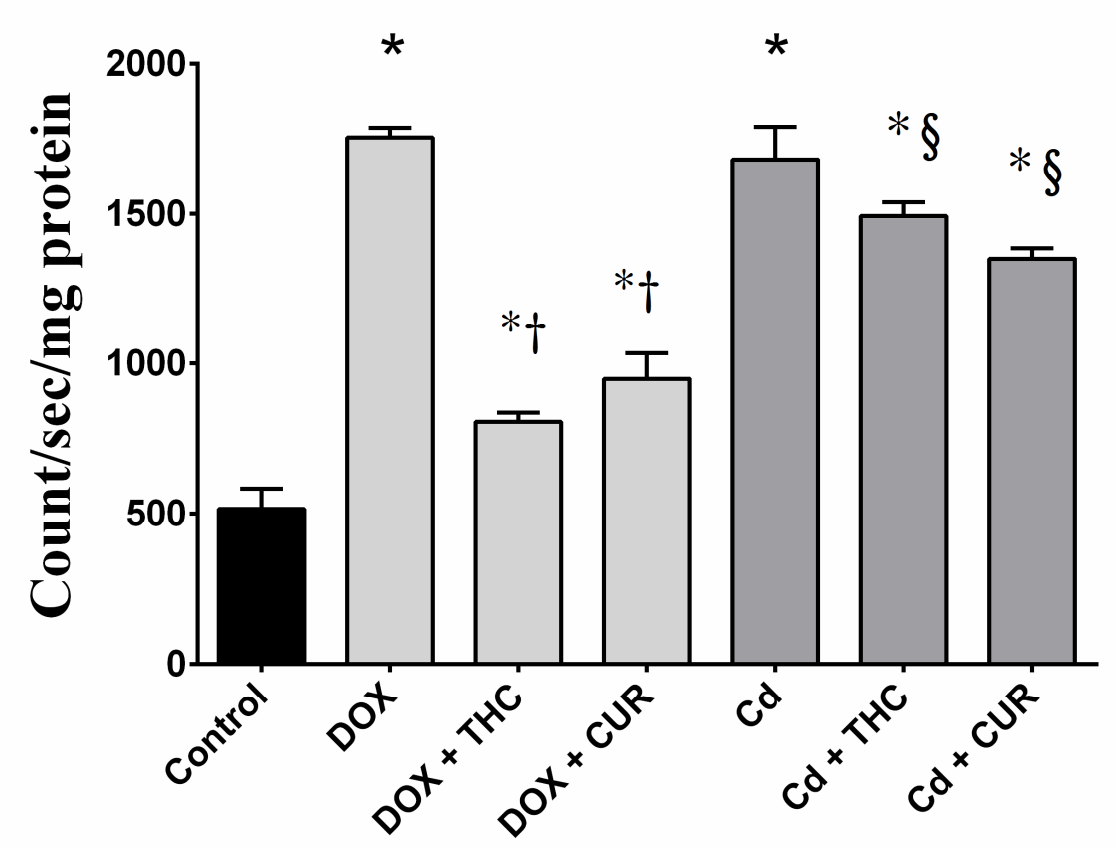

Figure 4: Effect of THC and CUR on reactive oxygen species formation. Chang cells were cultured in $35 \mathrm{~mm}$ dishes, incubated with $6 \mu \mathrm{M} \mathrm{THC}$ and CUR for $24 \mathrm{~h}$ followed by co-treatment with $1 \mu \mathrm{M}$ DOX or $3 \mu \mathrm{M}$ Cd and further incubated for $3 \mathrm{~h}$. The formation of superoxide anion was determined by lucigenin-enhanced chemiluminescence assay. Each bar represents the mean \pm SEM from three experiments * $P<0.05$ compared with the control; ${ }^{\dagger} p<0.05$ compared with DOX-treated group; ${ }^{\S} p<0.05$ compared with Cd-treated group
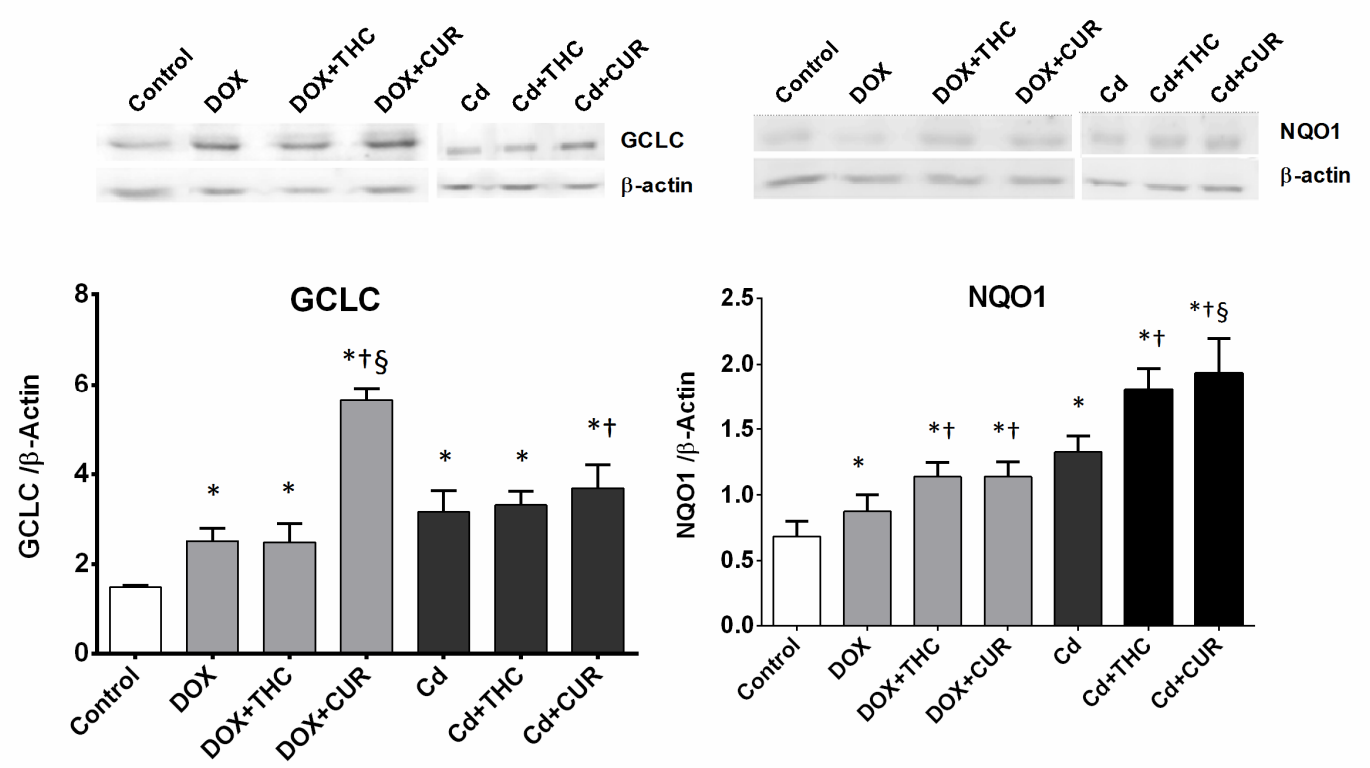

Figure 5: Western blot analysis of GCLC and NQO-1 expression in Chang cells. The cultured cells were pretreated with $6 \mu \mathrm{M} \mathrm{THC}$ and CUR for $24 \mathrm{~h}$ followed by co-treatment with $1 \mu \mathrm{M} \mathrm{DOX}$ or $3 \mu \mathrm{M} \mathrm{Cd}$ for $6 \mathrm{~h}$. The effects of treatments on GCLC (A) and NQO-1 expression (B) were analyzed by Western immunoblotting. The images shown are representative of experiments with similar results. Each bar represents the mean \pm SEM, from three experiments. ${ }^{*} P<0.05$ compared with control; ${ }^{\dagger} p<0.05$ compared with DOX treated group; ${ }^{\ddagger} p<0.05$ compared with Cd-treated group; ${ }^{\S} p<0.05$ compared with THC-treated group at the corresponding treatment

\section{DISCUSSION}

The present experiments provide evidence that THC and CUR have the ability to induce GCLC and NQO-1 protein expression and also have ability to induced Nrf2 translocation in Chang cells. In DOX and Cd-induced cytotoxicity models, CUR was slightly more potent than THC 
in the cytoprotective effect. The cytoprotective effect was associated with suppression of ROS and the induction of GCLC and NQO-1 protein expression. Moreover, there is some distinction between THC and CUR in induction of antioxidant enzyme expression.

An increase in expression of GCLC and NQO1 has been linked with the activation of Nrf-2 by several agents including CUR. We observed that CUR induced Nrf-2 nuclear translocation and up regulation of GCLC and NQO1 protein expression. These results are consistent with those obtained in previous studies [14,15]. Interestingly, our study provides evidence that THC can induce Nrf2 nuclear translocation and activation of GCLC and NQO1 protein expression, similar to CUR.

CUR-induced activation Nrf2 may be associated with cellular oxidants where it is probably related to the presence of two double bonds conjugated to $\beta$-diketone in the structure of CUR [16]. In this study, THC, which lacks two double bonds, was able to activate Nrf2 nuclear translocation and subsequently activated the GCLC and NQO1 expression. It is possible that activation of Nrf2 by THC is through some mechanisms distinct from CUR. The present study demonstrates, for the first time, that THC can induce GCLC and NQO-1 expression and is associated with activation of Nrf2 nuclear translocation in Chang liver cells.

DOX induces cytotoxicity by the production of ROS through the redox cycling of DOX using the mitochondrial enzymes. This mechanism may be associated with DOX-induced cardiotoxicity [17]. Oxidative stress and impairment of anti-oxidant defense system are also considered as critical events in Cd-induced toxicity. The cellular prooxidative stress induced by $\mathrm{Cd}$ is most likely mediated by disruption of redox homeostasis [18]. Therefore, inhibiting generation of ROS by anti-oxidants could ameliorate DOX- or Cdinduced cytoxicity. In the present study, pretreatment with THC and CUR showed antioxidant activity by suppression of the DOX- and Cd-generated ROS. THC and CUR are apparently less effective in scavenging the ROS generated by $\mathrm{Cd}$ than DOX model. The less efficiency of THC and CUR in suppressing Cdinduced superoxide formation is associated with the less efficient cytoprotective effect in $\mathrm{Cd}$ model than the DOX- model.

Besides the free radical scavenging activity of THC and CUR which have previously been reported [7], the inhibition of xenobiotic-induced ROS production is probably due to up-regulation of antioxidant gene expression including GCLC and NQO1 [19]. It should be noted that DOX and $\mathrm{Cd}$ themselves could also induce expression of antioxidant enzymes, probably as an adaptive response for cell survival. The presence of THC and CUR further increased the expression of the enzymes and the significant increase of cytoprotective effect. This cytoprotective effects may be attributable to the ability to scavenge ROS and enhance the antioxidant system by upregulation of GCLC and NQO1 enzymes.

\section{CONCLUSION}

The findings of this study suggest that $\mathrm{THC}$ and CUR have comparable effects on Nrf2 activation and its regulated enzyme expression, i.e., NQO1 and GCLC protein expression. With regard to the cytoprotection of THC and CUR against chemical toxicants in present study models, CUR is slightly stronger than THC. The mechanism of cytoprotection may be attributed to suppression of Nrf 2-regulated enzymes, GCLC and NQO1.

\section{ACKNOWLEDGEMENT}

This work was supported by a grant from Thailand Research Fund (TRF) under grant number: MRG 5480202. Curcumin and tetrahydrocurcumin were generous gifts from Praphassorn Surawattanawan, $\mathrm{PhD}$, of the Research and Development Institute, Government Pharmaceutical Organization, Bangkok, Thailand.

\section{REFERENCES}

1. Lopez-Lazaro M. Anticancer and carcinogenic properties of curcumin: considerations for its clinical development as a cancer chemopreventive and chemotherapeutic agent. Mol Nutr Food Res 2008; 52(Supp/ 1): S103-S127.

2. Cheng AL, Hsu CH, Lin JK, Hsu MM, Ho YF, Shen TS, Ko JY, Lin JT, Lin BR, Ming-Shiang $W$ et al. Phase I clinical trial of curcumin, a chemopreventive agent, in patients with high-risk or pre-malignant lesions. Anticancer Res 2001; 21(4B): 2895-2900.

3. Lao CD, Ruffin MTt, Normolle D, Heath DD, Murray SI, Bailey JM, Boggs ME, Crowell J, Rock CL, Brenner $D E$. Dose escalation of a curcuminoid formulation. BMC Complement Altern Med 2006; 6: 10.

4. Pan MH, Huang TM, Lin JK. Biotransformation of curcumin through reduction and glucuronidation in mice. Drug Metab Dispos 1999; 27(4): 486-494.

5. Nakmareong $S$, Kukongviriyapan $U$, Pakdeechote $P$, Donpunha W, Kukongviriyapan V, Kongyingyoes $B$, Sompamit K, Phisalaphong C. Antioxidant and vascular protective effects of curcumin and 
tetrahydrocurcumin in rats with L-NAME-induced hypertension. Naunyn Schmiedebergs Arch Pharmacol 2011; 383(5): 519-529.

6. Rajeswari A, Sabesan M. Inhibition of monoamine oxidase- $B$ by the polyphenolic compound, curcumin and its metabolite tetrahydrocurcumin, in a model of Parkinson's disease induced by MPTP neurodegeneration in mice. Inflammopharmacology 2008; 16(2): 96-99.

7. Okada K, Wangpoengtrakul C, Tanaka T, Toyokuni S, Uchida K, Osawa T. Curcumin and especially tetrahydrocurcumin ameliorate oxidative stressinduced renal injury in mice. J Nutr 2001; 131(8): 2090-2095.

8. Surh YJ, Kundu JK, Na HK, Lee JS. Redox-sensitive transcription factors as prime targets for chemoprevention with anti-inflammatory and antioxidative phytochemicals. J Nutr 2005; $135(12$ Suppl): 2993S-3001S.

9. Dinkova-Kostova AT, Fahey JW, Talalay P. Chemical structures of inducers of nicotinamide quinone oxidoreductase 1 (NQO1). Methods Enzymol 2004; 382: 423-448.

10. Aguirre $P$, Valdes $P$, Aracena-Parks $P$, Tapia V, Nunez MT. Upregulation of gamma-glutamate-cysteine ligase as part of the long-term adaptation process to iron accumulation in neuronal SH-SY5Y cells. Am J Physiol Cell Physiol 2007; 292(6): C2197-2203.

11. Nakmareong S, Kukongviriyapan U, Pakdeechote $P$, Kukongviriyapan $V$, Kongyingyoes $B$, Donpunha $W$, Prachaney $P$, Phisalaphong C. Tetrahydrocurcumin alleviates hypertension, aortic stiffening and oxidative stress in rats with nitric oxide deficiency. Hypertens Res 2012; 35(4): 418-425.

12. Tusskorn $O$, Prawan A, Senggunprai L, Kukongviriyapan $U$, Kukongviriyapan V. Phenethyl isothiocyanate induces apoptosis of cholangiocarcinoma cells through interruption of glutathione and mitochondrial pathway. Naunyn Schmiedebergs Arch Pharmacol 2013; 386(11): 1009-1016.

13. Prawan A, Buranrat B, Kukongviriyapan U, Sripa $B$, Kukongviriyapan $V$. Inflammatory cytokines suppress $N A D(P) H$ :quinone oxidoreductase-1 and induce oxidative stress in cholangiocarcinoma cells. J Cancer Res Clin Oncol 2009; 135(4): 515-522.

14. Dickinson DA, lles KE, Zhang $H$, Blank V, Forman HJ. Curcumin alters EpRE and AP-1 binding complexes and elevates glutamate-cysteine ligase gene expression. FASEB J 2003; 17(3): 473-475.

15. Gao S, Duan X, Wang X, Dong D, Liu D, Li X, Sun G, Li $B$. Curcumin attenuates arsenic-induced hepatic injuries and oxidative stress in experimental mice through activation of Nrf2 pathway, promotion of arsenic methylation and urinary excretion. Food Chem Toxicol 2013; 59: 739-747.

16. Anand $P$, Thomas SG, Kunnumakkara $A B$, Sundaram $C$, Harikumar $K B$, Sung $B$, Tharakan ST, Misra $K$, Priyadarsini IK, Rajasekharan KN et al. Biological activities of curcumin and its analogues (Congeners) made by man and Mother Nature. Biochem. Pharm 2008; 76(11): 1590-1611.

17. Das J, Ghosh J, Manna P, Sil PC. Taurine suppresses doxorubicin-triggered oxidative stress and cardiac apoptosis in rat via up-regulation of PI3-K/Akt and inhibition of p53, p38-JNK. Biochem. Pharm 2011; 81(7): 891-909.

18. Cuypers A, Plusquin M, Remans $T$, Jozefczak M, Keunen E, Gielen H, Opdenakker K, Nair AR, Munters E, Artois $T J$ et al. Cadmium stress: an oxidative challenge. Biometals 2010; 23(5): 927-940.

19. Suphim B, Prawan A, Kukongviriyapan U, Kongpetch $S$, Buranrat $B$, Kukongviriyapan $V$. Redox modulation and human bile duct cancer inhibition by curcumin. Food Chem Toxicol 2010; 48(8-9): 2265-2272. 